\title{
Pemberdayaan masyarakat melalui pembuatan Selai Jeruk Kuok di Dusun Pulau Belimbing, Desa Kuok, Kec. Kuok, Kab. Kampar
}

\author{
Edo Saputra*, Emma Riftyan, Yossie Kharisma Dewi, \& Anthony Hamzah \\ Universitas Riau \\ * edo.saputra@lecturer.unri.ac.id
}

\begin{abstract}
Abstrak. Desa Kuok merupakan salah satu desa yang ada di kecamatan kuok yang memiliki luas wilayah 6000 Ha. Jumlah penduduk di desa ini sebanyak 8.352 orang. Mayoritas penduduk di desa kuok bermata pencaharian sebagai petani. Salah satu komoditas yang banyak dibudidayakan oleh petani adalah tanaman jeruk. Jeruk didesa ini masih dikelola dalam bentuk segar dan belum di jadikan produk turunan. Oleh karena itu Tim Pengabdian Unri melakukan diversifikasi produk turunan jeruk yaitu selai jeruk. Tujuan dilakukannya pengabdian masyarakat ini untuk mengatasi pembusukan buah jeruk pada saat panen raya dengan mengolah buah jeruk menjadi produk selai jeruk yang memiliki umur simpan yang lebih lama dan meningkatkan pendapatan masyarakat. Metode yang digunakan adalah survey, sosialisasi dan pelatihan. Pembuatan selai jeruk ini dimulai dengan pengupasan jeruk, lalu yang diambil hanya daging jeruk kemudian dihaluskan, lalu direbus sari jeruk hingga mendidih kemudian ditambahkan gula dan diasuk hingga suhu $105^{\circ} \mathrm{C}$, lalu selai tersebut diletakkan di dalam jar.
\end{abstract}

Kata kunci: jeruk, diversifikasi produk, selai jeruk, Desa Kuok, umur simpan

\begin{abstract}
Kuok Village is one of the villages in the Kuok sub-district which has an area of 6000 hectares. The population in this village is 8352 people. The majority of the population in the Kuok village works as farmers. One of the commodities that cultivated by farmers is the orange orchard. Oranges in this village are still managed in fresh form and have not been made into a by-product. Hence, the Unri Community Service Team diversified its oranges derivative products, namely marmalade. The purpose of this community service is to solve the decay of oranges during the harvest season by processing oranges into marmalade that can increase community income. The methods used are survey, socialization and training. The process of making this jam begins with peeling the oranges, then all that is taken is the oranges flesh then mashed, then boiled the orange juice until it boils, then added sugar and put it in until the temperature is $105^{\circ} \mathrm{C}$, then the jam is placed in a jar.
\end{abstract}

Keywords: orange, product diversification, marmalade, kuok village, shelf life

To cite this article: Saputra, E., E. Riftya.n, Y. K. Dewi., \& A. Hamzah. 2020. Pemberdayaan masyarakat melalui pembuatan Selai Jeruk Kuok di Dusun Pulau Belimbing, Desa Kuok, Kec. Kuok, Kab. Kampar. Unri Conference Series: Community Engagement 2: 269-274. https://doi.org/10.31258/unricsce.2.269-274

(C) 2020 Authors

Peer-review under responsibility of the organizing committee of Seminar Nasional Pemberdayaan Masyarakat 2020 


\section{PENDAHULUAN}

Pertanian memiliki peranan yang penting baik di sektor perekonomian ataupun pemenuhan kebutuhan pokok atau pangan, sehingga dapat meningkatkan perekonomian bagi petani. Pembangunan sektor pertanian diarahkan untuk meningkatkan produktivitas hasil pertanian guna memenuhi kebutuhan pangan masyarakat, kebutuhan industri dalam negeri, meningkatkan eksport, meningkatkan pendapatan petani, memperluas kesempatan kerja, serta mendorong kesempatan berusaha. Kabupaten Kampar merupakan penghasil jeruk terbanyak di Riau dengan jumlah produksi 1,865 ton (Badan Pusat Statistik Riau, 2016).

Desa Kuok merupakan salah satu desa yang ada di kecamatan kuok yang memiliki luas wilayah $6.000 \mathrm{Ha}$ dan terletak pada ketinggian $45 \mathrm{~m}$ dpl. Jumlah penduduk di desa ini sebanyak 8.352 orang dengan jumlah lakilaki sebanyak 4239 orang dan jumlah perempuan sebanyak 4.113 orang. Mayoritas penduduk di desa kuok bermata pencaharian sebagai petani. Salah satu komoditas yang banyak dibudidayakan oleh petani adalah tanaman jeruk. Jeruk ini sangat banyak diminati oleh masyarakat, sehingga banyak masyarakat yang melakukan budaya jeruk. Semakin banyak yang melakukan budidaya jeruk maka produksi jeruk pun meningkat dan harga jual jeruk semakin bersaing.

Panen raya jeruk tidak dilakukan setiap bulan. Ketika panen raya jeruk terjadi, jumlah produksi meningkat drastis dan berdampak terhadap harga buah jeruk yang menurun serta buah jeruk tidak laku di pasaran. Hal ini mengakibatkan petani menjadi rugi, sehingga perlu adanya tindakan yang perlu dilakukan untuk mengatasi permasalahan ini yaitu dengan mengolah buah jeruk menjadi suatu produk yang umur simpannya lebih lama seperti selai.

Selai merupakan makanan berbentuk pasta yang diperoleh dari pemasakan bubur buah, gula dan dapat ditambahkan asam serta bahan pengental. Selai biasa digunakan sebagai pelengkap roti, isian kue kering dan bahan tambahan pada produk pangan yang lain. Selai yang berasal dari buah-buahan pada umumnya hanya kaya akan vitamin sementara kandungan mineral seperti kalsium ada hanya dalam jumlah kecil (Palupi, 2009). Selai termasuk produk awetan dari buah yang dihancurkan dan dicampur gula serta tanpa penambahan air dan memiliki tekstur yang lunak (Utomo, et.al., 2020). Dalam pembatan selai juga perlu diperhatikan konsentrasi gula, pektin dan asam agar diperoleh kondisi optimum dalam pembentukan gel, yaitu gula sebesar 65-70\%, pectin sebesar 0,75-1,5\% dan asam dengan $\mathrm{pH}$ 3,2-3,4 (Tandikurra et.al., 2019). Syarat mutu selalu diterapkan agar produk yang dihasilkan memiliki nilai gizi maupun keamanan yang dapat menjamin keselamatan dalam mengonsumsi nya. Kualitas selai buah yang baik dapat diketahui dari syarat mutu selai berdasarkan Standar Nasional Indonesia (SNI 01-3746-2008).

Berdasarkan uraian tersebut Tim Pengabdian Masyarakat memilih Desa Kuok yang bergerak dibidang pangan Kecamatan Kuok untuk diusulkan dalam program Pengabdian Kepada Masyarakat agar dapat berkembang dan mampu meningkatkan pendapatan usaha. Adanya kemampuan untuk menghasilkan produk turunan jeruk yang berkualitas dan memiliki nilai jual yang tinggi. Tujuan dilakukannya pengabdian masyarakat ini untuk mengatasi pembusukan buah jeruk pada saat panen raya dengan mengolah buah jeruk menjadi produk selai jeruk yang memiliki umur simpan yang lebih lama dan meningkatkan pendapatan masyarakat.

\section{METODE PENERAPAN}

Metode yang digunakan pada kegiatan ini adalah sebagai berikut: melakukan survei, persiapan sosialisasi program, melaksanakan sosialisasi dan pelatihan.

\section{a. Survei}

Melakukan penjajakan dan pendekatan terhadap pemerintah desa termasuk Kepala Desa, ketua PKK, petani, dan masyarakat Desa Kuok, dilakukan selama satu minggu.

\section{b. Persiapan dan Sosialisasi program}

- Mempersiapkan alat-alat praktek yang ada kaitannya dengan produk tersebut. Persiapan ini memerlukan waktu 3 minggu.

- Mahasiswa kukerta melakukan sosialisasi pprogram pembuatan selai kepada masyarakat desa kuok

\section{c. Melaksanakan sosialisasi dan pelatihan}

Menerapkan praktek teknologi pengolahan jeruk tepat guna berbahan baku jeruk, air dan gula. Kegiatan ini dilakukan bersama dengan masyarakat Desa Kuok yang dibimbing oleh Tim Pengabdian Kepada 
Masyarakat.kegiatan ini dilaksanakan di Pondopo tepi sungai Dsn. Pulau Belimbing II Desa Kuok pada hari Sabtu, 18 Juli 2020 pukul 14.00 WIB

\section{Alat Ukur Ketercapaian}

Hasil kegiatan Pengabdian Kepada Masyarakat yang menjadi alat ukur ketercapaiannya kegiatan sosialisasi dan pelatihan pembuatan produk selai jeruk yang dilaksanakan di Desa Kuok.Masyarakat menanggapi pengetahuan tentang produk tersebut mudah dikerjakan, dapat membantu perekonomian masyarakat setempat, dan produk dapat dijadikan oleh-oleh khas kuok.

\section{HASIL DAN KETERCAPAIAN}

Pelatihan tersebut pembuatan selai jeruk ini dilakukan di Dusun Pulau Belimbing II pada tanggal 18 Juli 2020. Pelatihan yang pertama terkait praktik membuat selai jeruk dengan jeruk siam khas Pulau Belimbing. Tim Kukerta Unri melakukan pelatihan ini dengan tujuan agar warga setempat dapat mengolah buah lokal ini dengan nilai jual yang bertambah serta memperluas pasar. Kegiatan pengabdian ini didukung oleh ibu-ibu PKK, Kepala desa Kuok dan POKDARWIS.

Kegiatan ini dilaksanakan untuk menambah pendapatan penduduk setempat dan memasarkannya menjadi lebih luas. Luaran yang dihasilkan masyarakat dapat membuat produk selai jeruk lokal dan memasarkannya. Dalam pelaksanaan kegiatan ini tidak ada kesulitan dalam memproduksi produk selai jeruk, hanya saja belum ditemukan rasa yang stabil untuk setiap pembuatan produk selai. Produk selai ini memiliki peluang yang cukup besar dipasar, karena sejauh ini untuk produksi produk selai jeruk masih minim ditemukan sehingga tidak akan mengalami kerugian saat memasarkannya. Keunggulan dari kegiatan ini adalah masyarakat mampu memproduksi selai sehingga tidak hanya dijual dalam bentuk segar yang memiliki resiko yang lebih besar, dengan produk turunan jeruk ini dapat memperpanjang umur simpan dan memiliki nilai jual yang tinggi. Kelemahannya adalah minimnya pengetahuan masyarakat mengenai teknologi yang digunakan sebagai alat pemasaran secara online.

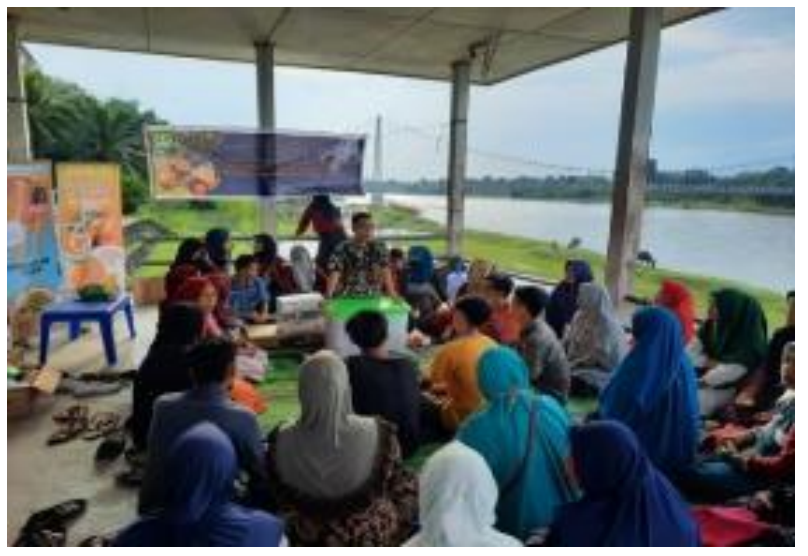

Gambar 1 menunjukkan arahan dan bimbingan dari para dosen mengenai produk turunan jeruk. Dosen memberikan informasi mengenai kandungan jeruk dan tahapan-tahapan dalam pembuatan selai jeruk.

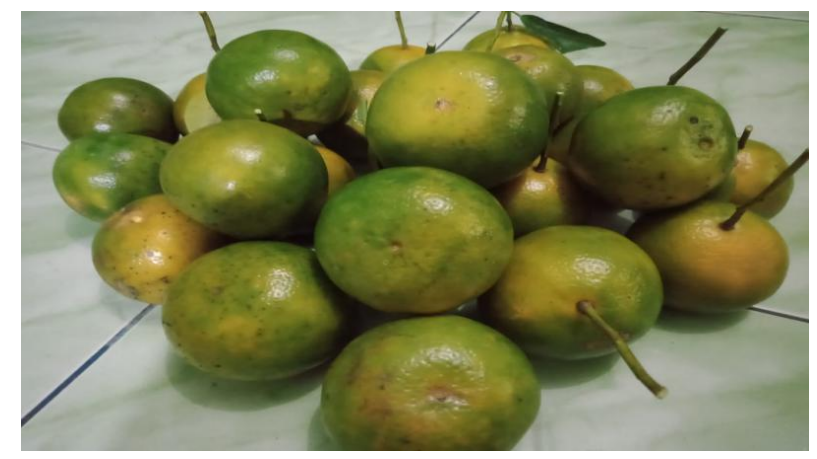

Gambar 2. Jeruk Pulau Belimbing 
Gambar 2 merupakan jeruk khas kuok yang akan diolah menjadi selai jeruk. Ciri khas tersebut adalah rasa yang manis dan kulit yang kehijauan.
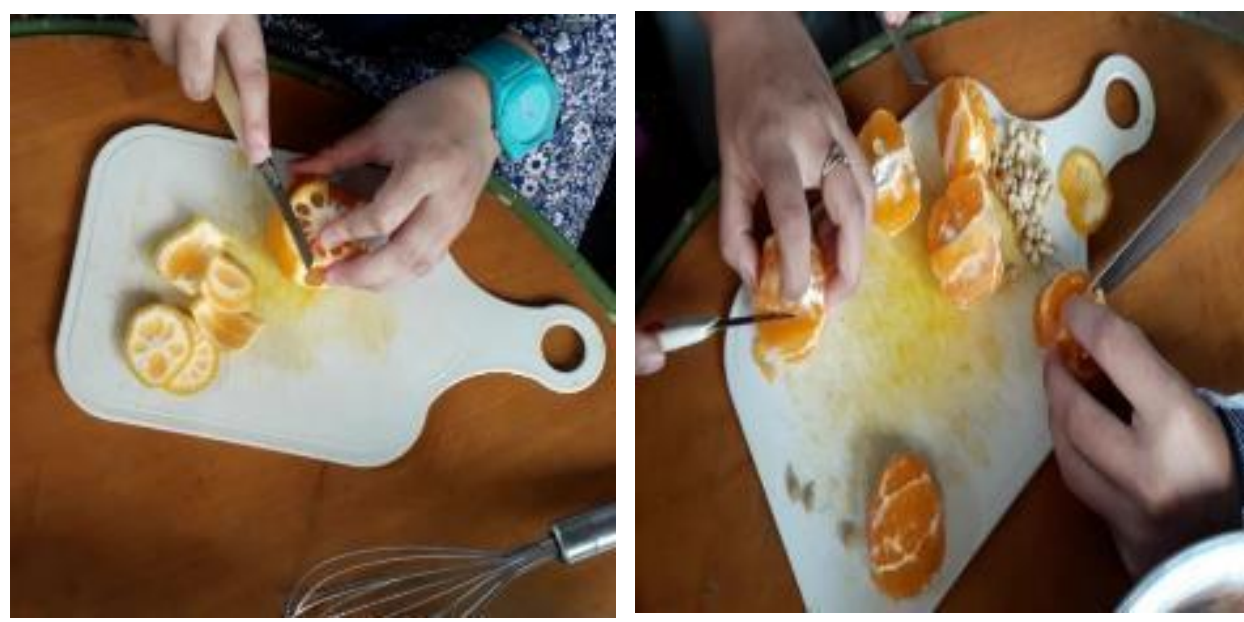

Gambar 3 merupakan proses pengupasan jeruk. Kulit dan biji jeruk di pisahkan dari daging buah.

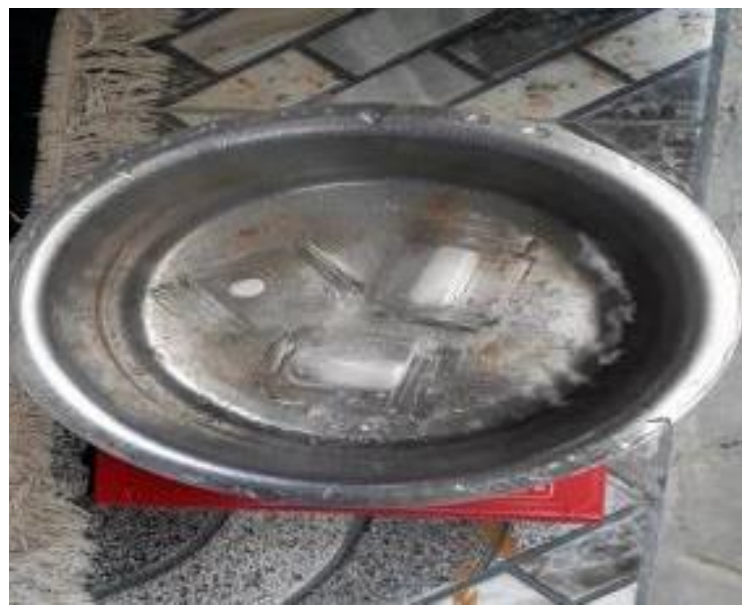

Gambar 4. Sterilisasi wadah jar

Gambar 4 merupakan proses sterilisasi wadah jar dengan cara merebusnya selama 15-20 menit. Tujuannya agar produk selai yang dihasilkan tidak terkontaminasi oleh mikroorganisme sehingga dapat memperpanjang umur simpan dari selai jeruk.
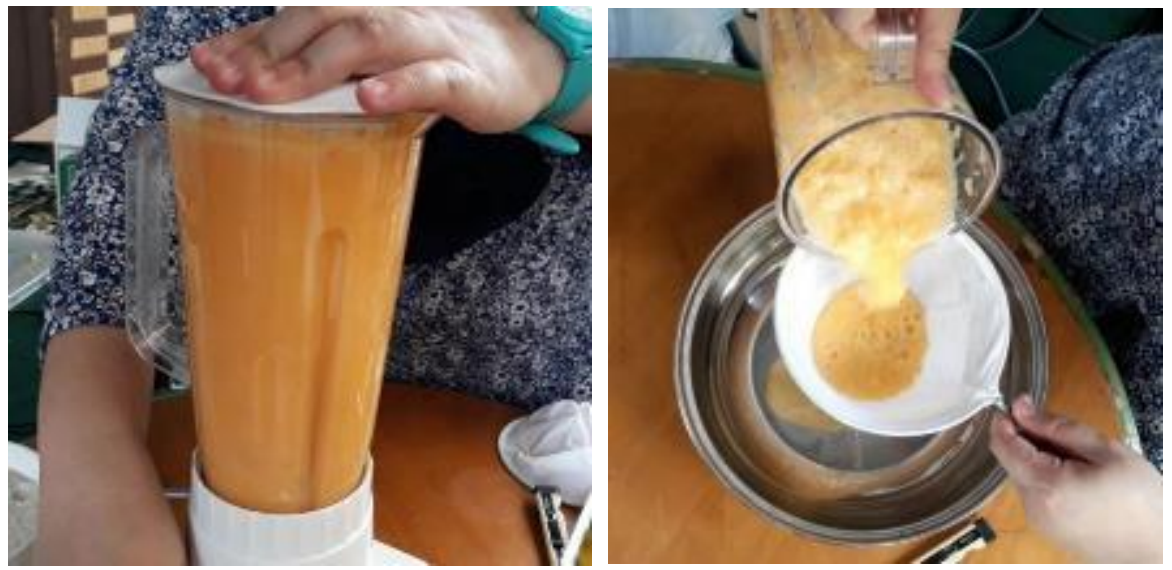

Gambar 5. Penghalusan daging buah jeruk 
Gambar 5 merupakan proses penghalusan daging buah jeruk dan menyaring sari buah jeruk. Sari buah di letakkan kedalam wadah panci untuk di rebus dan ditambahkan sedikit asam sitrat. Ampas jeruk dimasukkan kedalam wadah kain kemudian digantingkan di dalam panci. Ampas buah tersebut mengandung pectin yang berguna dalam proses pengentalan selai jeruk. Rebuslah dengan api sedang hingga mendidih.

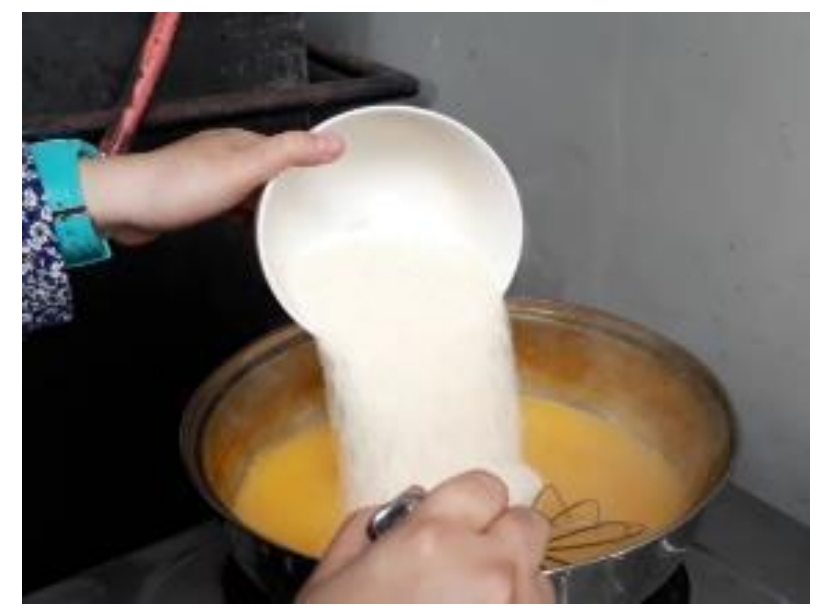

Gambar 6. Penambahan Gula

Gambar 6 merupakan proses penambahan gula. Proses penambahan gula ini berfungsi untuk membuat rasa selai menjadi manis dan membuat selai jeruk menjadi mengental. Kemudian diaduk hingga suhu larutan selai tersebut $105^{\circ} \mathrm{C}$. Suhu diukur menggunakan thermometer.

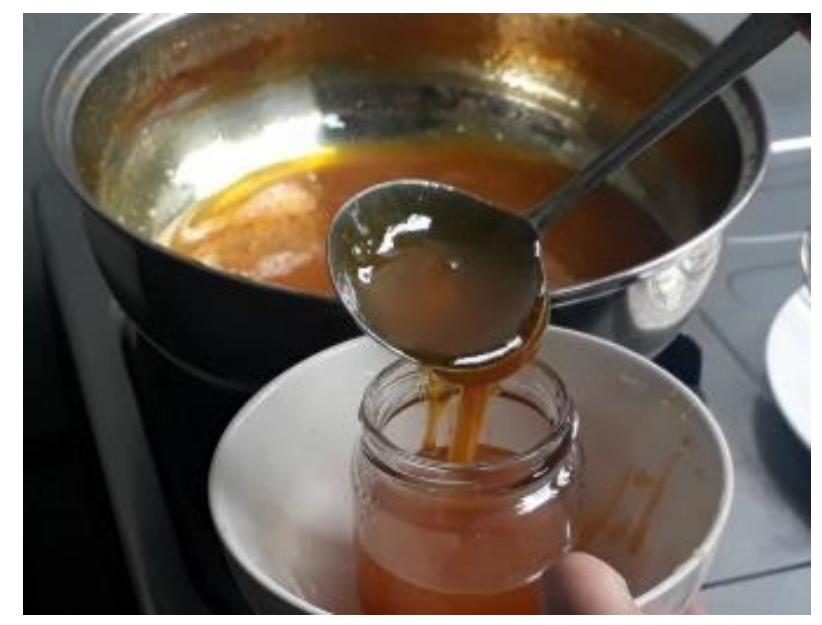

Gambar 7. Peletakan selai kedalam gelas jar

Gambar 7 merupakan gambar plating selai jeruk dalam gelas jar. Tingkat viskositas dari selai jeruk saat masih panas memang agak encer. Agar viskositasnya pas (tidak encer), selai jeruk harus didinginkan bersuhu hampir sama dengan suhu ruangan. 


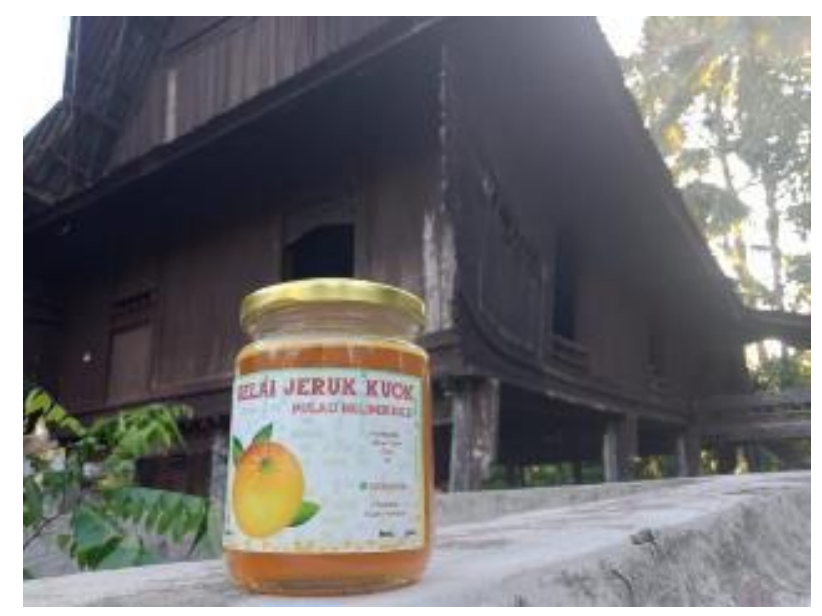

Gambar 8. Merupakan produk selai jeruk yang sudah dikemas dengan menggunakan gelas jar dan label.

\section{KESIMPULAN}

Produk selai jeruk kuok sudah dilaksanakan di Dusun Pulau Belimbing, Desa Kuok, Kecamanatan Kuok kepada Ibu PKK, ibu-ibu anggota POKDARWIS, masyarakat dusun Pulau Belimbing I dan II. Pembuatan selai jeruk ini tidak terlalu sulit dan dapat dikerjakan dengan menggunakan peralatan yang sederhana serta dengan bahan yang cukup mudah ditemukan yaitu air, gula dan jeruk. Sehingga saat panen raya, masyarakat dapat memanfaatkan jeruk yang tidak laku terjual menjadi produk turunan jeruk yaitu selai jeruk yang menambah nilai jual dari jeruk itu sendir serta menambah umur simpan dari produk turunan jeruk ini.

\section{UCAPAN TERIMA KASIH}

Kegiatan pengabdian kepada masyarakat ini merupakan pengabdian DIPA Universitas Riau. Tim pengabdian mengucapkan terimakasih kepada Universitas Riau yang telah mendanai sehingga kegiatan pengabdian dapat dilakukan.

\section{DAFTAR PUSTAKA}

Badan Pusat Statistik. 2016. Provinsi Riau Dalam Angka 2016. Riau,Badan Pusat Statistik Provinsi Riau.

Badan Standarisasi Nasional. 2008. SNI 3746-2008:Syarat Mutu Selai Buah. Badan Standarisasi Nasional. Jakarta.

Kementerian Kesehatan Republik Indonesia. 2017. Petunjuk Teknis Pemberian Makanan Tambahan. Kementerian Kesehatan Republik Indonesia, Jakarta.

Palupi, S., Hamidah S. dan Purwati S. 2009. Peningkatan Produktivitas Hasil Olahan Salak Melalui Diversifikasi Sekunder untuk Mendukung Pengembangan Kawasan Agropoitan. Jurnal Inotek, 13(1).

Pujimulyani, D. 2009. Teknologi Pengolahan Sayur-Sayuran dan Buah-Buahan. Graha Ilmu. Yogyakarta.

Tandikurra, D.T., Lalujan, L.E., dan Sumual, M.F. 2019. Pengaruh Penambahan Sari Jeruk Nipis Terhadap Sensori Selai Tomat (Lycopersicum esculentum Mill.). Jurnal Teknologi Pertanian, 10(2).

Utomo, R.C., Sani, E.Y., dan Haryati, S. 2020. Konsentrasi Gula Pasir Terhadap Karakteristik Fisikokimia dan Organoleptik Selai Timun Krai (Curcumis sp). Jurnal Teknologi Pangan dan Hasil Pertanian, 15(1), 1-9. 